\title{
NO chemiluminescence in exhaled air: interference of compounds from endogenous or exogenous sources
}

\author{
N. Binding, W. Müller, P.A. Czeschinski, U. Witting
}

\begin{abstract}
NO chemiluminescence in exhaled air: interference of compounds from endogenous or exogenous sources. N. Binding. W. Müller, P.A. Czeschinski, U. Witting. (C)ERS Journals Ltd 2000.

ABSTRACT: Nitric oxide determination in exhaled air using chemiluminescence analysers is increasingly used, but may be affected by various other components of the air sample. The influence of several compounds originating from endogenous or exogenous sources on NO readings has been studied.

Defined amounts of water vapour, carbon dioxide, acetone, heptane, acetonitrile, oxygen, nitrous oxide and enflurane were added to air samples with NO concentrations 0-250 parts per billion.

Marked and significant decreases in NO readings, which strongly depend on the concentration of the respective interfering compound, were found for water vapour $\left(0.155 \%\right.$ per $1 \%$ relative humidity), carbon dioxide $\left(1.97 \%\right.$ per $1 \% \mathrm{CO}_{2}$ volume/volume (v/v)) and nitrous oxide $\left(0.608 \%\right.$ per $\left.1 \% \mathrm{v} / \mathrm{v}_{2} \mathrm{O}\right)$. While acetone in concentrations up to $8.5 \%$ v/v had no measurable effect on NO readings, heptane and acetonitrile led to marked decreases. Oxygen in concentrations of up to $95 \%(\mathrm{v} / \mathrm{v}) \mathrm{had}$ no effect on NO determination. NO readings were markedly decreased by $>10 \%$ per $1 \%(\mathrm{v} / \mathrm{v})$ of the anaesthetic enflurane. However, due to large variations in NO values, these decreases were not statistically significant. Furthermore, enflurane reacted with the molybdenum converter of the $\mathrm{NO}_{\mathrm{x}}$ analyser in use, resulting in major damage to the instrument.
\end{abstract}

Eliminating, or at least considering, interferences by compounds present in exhaled air is an urgent prerequisite for reliable and precise nitric oxide determination. Eur Respir J 2000; 16: 499-503.

Nitric oxide (NO) produced via NO synthases is detectable in exhaled air of healthy subjects [1]. As NO plays an important role in physiology (e.g. neurotransmission, vascular regulation, airway function regulation [2]) and the pathophysiology of different diseases (e.g. inflammatory airway diseases [3-5], chronic heart disease [6], respiratory tract infections [7], septic shock [8], systemic sclerosis [9]) the determination of exhaled NO might be of considerable diagnostic and therapeutic importance. Monitoring NO in exhaled air might thus provide a noninvasive method for the clinical control of diseases and especially of the success of therapeutic interventions. The hypothesis that NO exhalation is elevated in asthma, sepsis, and airway as well as pulmonary inflammations [8, $10,11]$ or decreased in chronic heart diseases [6], has been confirmed by numerous working groups.

The measurement of exhaled NO is performed using chemiluminescence detectors providing the required measurement range [12] of $0.1-10,000$ parts per billion (ppb). $\mathrm{NO}$ is oxidized to high energy, excited state $\mathrm{NO}_{2} *$ by reaction with ozone $\left(\mathrm{O}_{3}\right)$. When passing to the ground state, a fraction of the excess energy of $\mathrm{NO}_{2}{ }^{*}$ is dissipated by emission of photons (chemiluminescence); this is used for quantitative detection. Major fractions of energy are dissipated by interactions with other components of the analysed sample in the reaction chamber. The extent of this energy transfer (quenching) by collisions with other molecules is determined mainly by the chamber pressure
Institute of Occupational Medicine, University of Münster, Münster, Germany.

Correspondence: N. Binding, Institut für Arbeitsmedizin der Westfälischen Wilhelms-Universität Münster, Robert-KochStr. 51, D-48149 Münster, Germany. Fax: 492518356275 .

Keywords: chemiluminescence

enflurane

interferences

nitric oxide

nitrous oxide

water vapour

Received: December 311999

Accepted after revision May 22000 and the sample composition $[13,14]$. Thus, variations in sample composition may influence the chemiluminescence signal.

Exhaled air represents a complex mixture of substances with more than 300 detected volatile compounds of exogenous or endogenous origin $[15,16]$, which might have considerable effects on the result of $\mathrm{NO}$ measurement. These are primarily carbon dioxide $\left(\mathrm{CO}_{2}\right)$ and water, but also different substances originating from metabolic processes, e.g. heptane, acetonitrile, and acetone. Elevated exhalation of some of these compounds occurs in certain diseases, e.g. acetone in heart diseases [17] and diabetes mellitus [18], pentane in arthritis and acute myocardial infarction [19] or ethanol in arthritis, lung cancer, and schizophrenia [20]. Furthermore, substances from exogenous sources, especially when applied in high doses during medical treatment (e.g. volatile anaesthetics or oxygen during oxygen therapy), might influence NO quantification. In this study, interferences of $\mathrm{CO}_{2}$, water, heptane, acetonitrile, acetone, $\mathrm{N}_{2} \mathrm{O}$ and enflurane with the chemiluminescence process are investigated to improve reliability and reproducibility of NO measurements in exhaled air.

\section{Methods}

$\mathrm{NO}$ was analysed with a TE $42 \mathrm{~S} \mathrm{NO}_{\mathrm{x}}$ analyser (Thermo Environmental Instruments, Franklin, Massachusetts, USA) 
equipped with two separate channels for $\mathrm{NO}$ and $\mathrm{NO}_{2}$ measurements. The detection range for $\mathrm{NO}$ was $0.01-240$ $\mathrm{ppb}$, the sampling rate was $1 \mathrm{~L} \cdot \mathrm{min}^{-1}$. A special feature of this analyser is that NO-free gas ("zero gas") is produced from aliquots of the sampled mixtures by cyclic passage through an internal prereaction chamber. NO is completely oxidized to $\mathrm{NO}_{2}$ before passing the main reaction chamber. Thus, a sample-specific zero correction for background noise is performed by comparison of the signals of internal zero gas and sample. For the determination of $\mathrm{NO}_{2}$, the sample is alternatingly passed through a molybdenum converter where a complete reduction of $\mathrm{NO}_{2}$ to $\mathrm{NO}$ is performed prior to the oxidation step in the ozone reaction chamber. From the resulting total value for $\mathrm{NO}_{2}$ and $\mathrm{NO}$, the concentration of $\mathrm{NO}_{2}$ is calculated by subtracting the NO value assessed without the reduction step.

Samples with defined NO concentrations were prepared by diluting a certified reference gas (10 ppm NO in $\mathrm{N}_{2}$; Westfalen AG, Münster, Germany) either with $\mathrm{N}_{2}$ of high purity (99.995\%; Westfalen AG) for instrument calibration or with certified NO-free air (Westfalen AG) for all other measurements. Addition of further components was performed by dividing the air stream and bubbling air via a bypass through a flask with the respective liquid component (water, heptane, acetone, acetonitrile, enflurane) or by adding gaseous components $\left(\mathrm{CO}_{2}, \mathrm{O}_{2}\right.$, nitrous oxide) via high precision valves and flow controllers. Thorough mixing of the components was accomplished by passing the air stream through a tube with an irregular inner surface generating a turbulent stream. Concentrations of added gaseous components were adjusted by flow control, and those of liquid components by variation of the bypass air flow. Figure 1 shows a schematic drawing of the open tube mixing device providing a continuous sample flow. High precision valves, tubings and fittings, and flow controllers were of polytetrafluoroethylene, stainless steel or glass. The $\mathrm{CO}_{2}$ concentration (after dilution with air) and the humidity of the samples were monitored with a Testo 400 multifunctional sensor (Testo, Lenzkirch, Germany). The resulting concentrations of heptane, acetone, acetonitrile, $\mathrm{N}_{2} \mathrm{O}$, and enflurane were determined by gas chromatography with an HP 5890 chromatograph with FID (or ECD for $\mathrm{N}_{2} \mathrm{O}$ and enflurane), HP ChemStation soft-

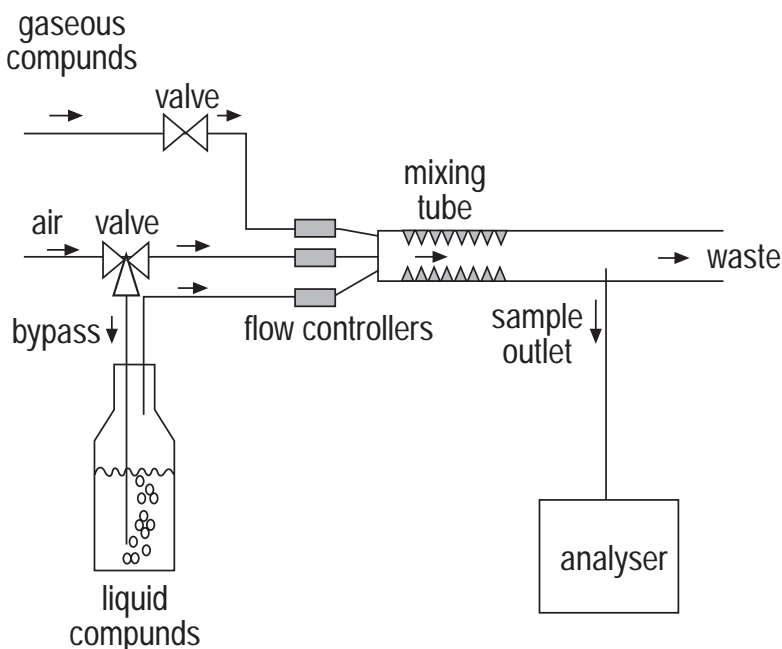

Fig. 1. - Schematic drawing of the open tube mixing device. ware, $30 \mathrm{~m}$ HP-Plot molecular sieve 5 A column for $\mathrm{N}_{2} \mathrm{O}$ (ID: $0.53 \mathrm{~mm}$, film thickness $25 \mu \mathrm{m}$ ) or $50 \mathrm{~m} \mathrm{HP}-5$ capillary column for all other substances (ID: $0.32 \mathrm{~mm}$, film thickness: $0.52 \mu \mathrm{m}$ ) (Hewlett Packard, Palo Alto, USA). $\mathrm{N}_{2}$ was used as carrier gas in all separations.

Samples were taken near the end of the open tube mixing device (fig. 1). To prevent aspiration of external air, the sample flow was kept constantly above the analyser's sampling rate of $1 \mathrm{~L} \cdot \mathrm{min}^{-1}$ (total sample flow: 2 $\mathrm{L} \cdot \mathrm{min}^{-1}$ ).

The influence of $\mathrm{CO}_{2}$ on $\mathrm{NO}$ determination was tested with $\mathrm{CO}_{2}$ concentrations of $1-10 \%$. The influence of water was measured in a range of $0-92 \%$ relative humidity; concentration ranges for the other components were: heptane: $0-3.5 \%$, acetonitrile: $0-1.7 \%$, acetone: $0-8.5 \%$, oxygen: $20-95 \%$, enflurane: $0-2 \%, \mathrm{~N}_{2} \mathrm{O}: 0-60 \%$. NO concentrations were $0-250 \mathrm{ppb}$. Measurements were performed in triplicate for each sample.

\section{Results}

A significant decrease in NO readings was found when $\mathrm{CO}_{2}$ was added as interfering compound with concentrations of $1-10 \% \mathrm{v} / \mathrm{v}$. The slope of the calibration line for air containing 5\% (v/v) $\mathrm{CO}_{2}(0.865 \pm 0.014 ; \mathrm{p}<0.001 ; 95 \%$ confidence interval (CI) $0.849-0.881$ ) was significantly different from the line for $\mathrm{CO}_{2}$-free samples (line of identity) (fig. 2). The mean decrease was $1.97 \pm 0.62 \%$ per $1 \%$ (v/v) $\mathrm{CO}_{2}(\mathrm{p}<0.001)$ (fig. 3).

Humidification ( $92 \%$ relative humidity) led to a comparable decrease in readings. The slope of the calibration line was $0.815 \pm 0.021(\mathrm{p}<0.001 ; 95 \%$ CI $0.785-0.846)$. With increasing humidity, a mean decrease of $0.155 \pm$ $0.040 \%(\mathrm{p}<0.001)$ for each $1 \%$ relative humidity step was found.

The influence of some components of exhaled air originating from endogenous sources was studied for heptane, acetonitrile and acetone. While acetone in concentrations up to $8.5 \%(\mathrm{v} / \mathrm{v})$ had no measurable effect, heptane $(0.75-$ $3.5 \%(\mathrm{v} / \mathrm{v}))$ and acetonitrile $(0.8-1.7 \%(\mathrm{v} / \mathrm{v}))$ led to marked decreases in NO readings. However, in contrast to the findings with $\mathrm{CO}_{2}$ and humidity, the percentage of deviation decreased with increasing NO concentrations (fig. 4), thus pointing to different mechanisms of interference.

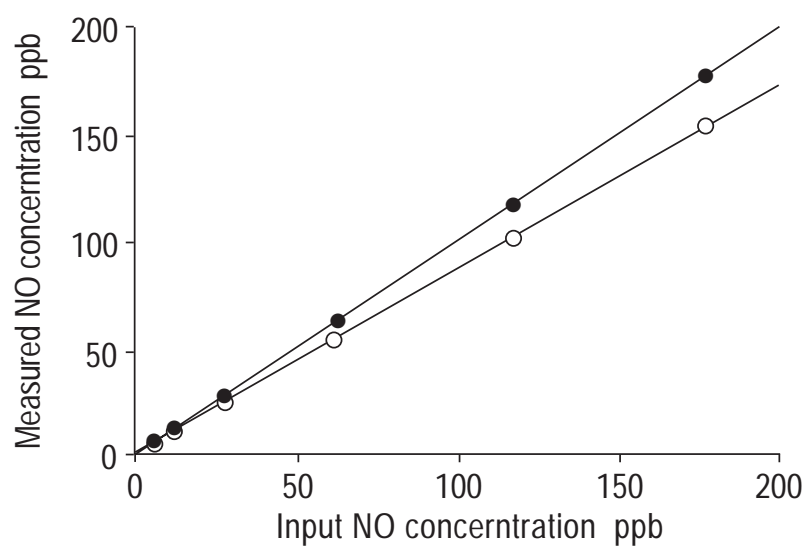

Fig. 2. - Calibration lines for nitric oxide (NO) in pure air $(\mathbf{O})$ and for $\mathrm{NO}$ in air containing $5 \%(\mathrm{v} / \mathrm{v}) \mathrm{CO}_{2}(\mathrm{O})$. ppb: parts per billion. 


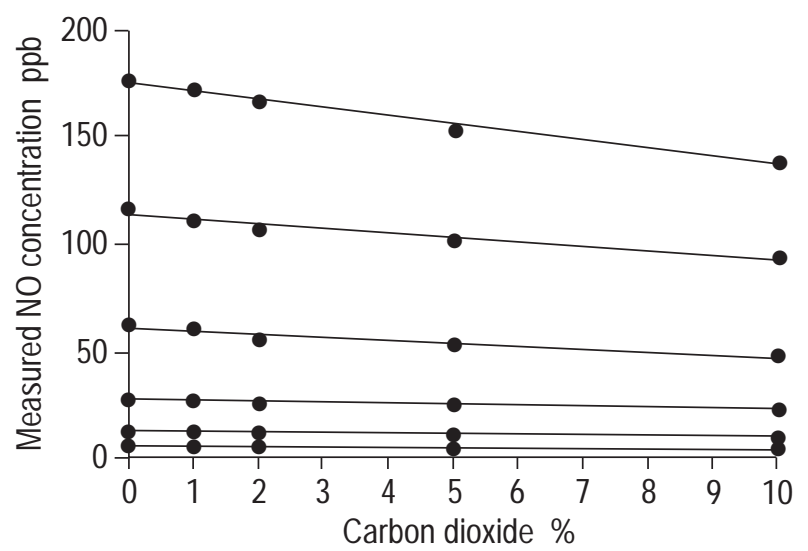

Fig. 3. - Decrease in nitric oxide (NO) readings with increasing $\mathrm{CO}_{2}$ concentration at different starting concentrations of NO.

During medical treatment of patients some compounds from exogenous sources, e.g. $\mathrm{O}_{2}$ from $\mathrm{O}_{2}$ therapy or volatile anaesthetics during and after anaesthesia, might interfere with NO measurement. Therefore the influence of high concentrations of $\mathrm{O}_{2}, \mathrm{~N}_{2} \mathrm{O}$, and enflurane on $\mathrm{NO}$ determination was studied. $\mathrm{O}_{2}$ in concentrations up to $95 \%$ $(\mathrm{v} / \mathrm{v})$ had no measurable effect on $\mathrm{NO}$ readings. $\mathrm{N}_{2} \mathrm{O}$ was added up to a concentration of $60 \%(\mathrm{v} / \mathrm{v})$, which is commonly used in anaesthesia. A significant decrease in NO readings was found (mean decrease per $1 \%(\mathrm{v} / \mathrm{v}) \mathrm{N}_{2} \mathrm{O}$ : $0.608 \pm 0.033 \%, \mathrm{p}<0.001)$. With a maximum $\mathrm{N}_{2} \mathrm{O}$ concentration of $60 \%(\mathrm{v} / \mathrm{v})$, the slope of the calibration line was $0.614 \pm 0.01(\mathrm{p}<0.001$, CI $0.602-0.626)$.

The influence of enflurane, a volatile halogenated anaesthetic, was investigated in common anaesthetic concentrations up to $2 \%(\mathrm{v} / \mathrm{v})$. Again a marked decrease of NO readings was found. Statistical analysis of the data revealed that due to the large variation of NO values measured and the poor linearity of the calibration line, this decrease was not significant (mean decrease per $1 \%(\mathrm{v} / \mathrm{v})$ enflurane: $10.2 \pm 7.9 \%, \mathrm{p}<0.87)$. The main reason for the poor reproducibility of NO determination was found in an unexpected reaction of enflurane with the analyser's molybdenum converter. Deposits of the reaction products (identified as

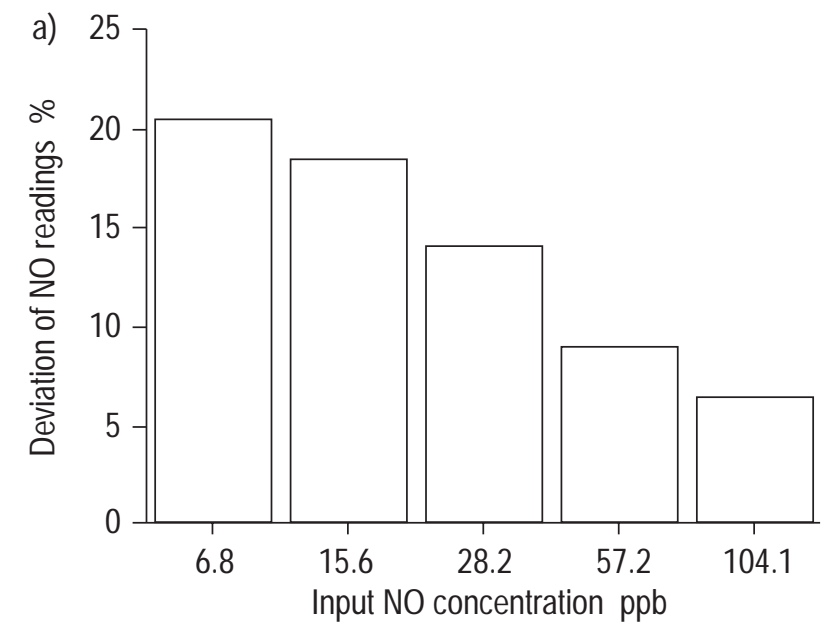

molybdenum oxichloride by mass spectrometric analysis) in nearly all internal tubings led to instrument failure. The reaction of molybdenum with enflurane and other halogenated compounds and its influence on the performance of the NO analyser has been further investigated, but the results would exceed the scope of this article and are to be published elsewhere.

\section{Discussion}

The results presented in this paper confirm that compounds present in exhaled air interfere with chemiluminescence detection of $\mathrm{NO} . \mathrm{CO}_{2}$ and water vapour as major constituents of exhaled air both led to significant reductions in NO readings. This is in agreement with findings reported by VAN DER MARK et al. [21], though there are some discrepancies in the percentage decrease: $1.04 \%$ [21] versus $1.97 \%$ (present study) decrease per $1 \%(\mathrm{v} / \mathrm{v})$ $\mathrm{CO}_{2}$ and $12.0 \%$ decrease at a water vapour pressure of $2.81 \mathrm{kPa}$ [21] versus $14.3 \%$ (present study) at a vapour pressure of $2.15 \mathrm{kPa}\left(\sim 92 \%\right.$ relative humidity at $\left.20^{\circ} \mathrm{C}\right)$. These discrepancies may be attributed to the different analysers used. Since low pressure in the reaction chamber reduces quenching effects [8], the higher values recorded in this study may be due to the chamber pressure of $40 \mathrm{kPa}$, which is considerably higher than that of 5.2 $\mathrm{kPa}$ in the analyser used by VAN DER MARK et al. [21]. However, both studies led to the same conclusions, which are discussed in detail by VAN DER MARK et al. [21] and are therefore only summarized in this paper.

The influence of $\mathrm{CO}_{2}$ in physiological concentrations of $\sim 4 \%$ on NO determination is limited and may be considered for the respective analyser. Differences between mixed expired and end-tidal $\mathrm{CO}_{2}$ concentrations up to $2 \%$ would lead to negligible variations in NO readings for concentrations exhaled by normal healthy humans, but might be of importance when exogenous NO in higher concentrations is administered to patients for therapeutic reasons. The influence of water vapour is more pronounced with a decrease of $14.3 \%$ at a sample temperature of $20^{\circ} \mathrm{C}$ and a relative humidity of $92 \%(\sim 2.15 \mathrm{kPa}$ water vapour pressure). With water-saturated exhaled air at

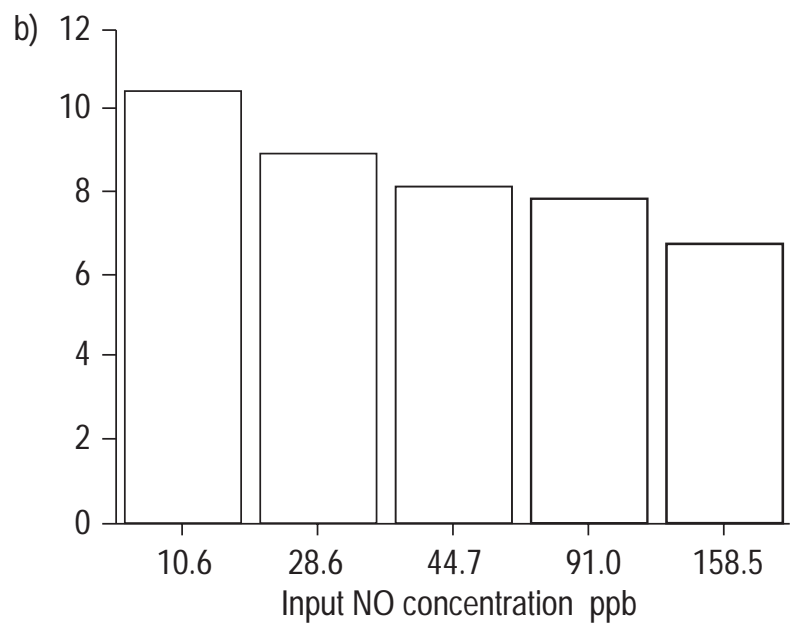

Fig. 4. - Deviation (\%) of nitric oxide readings as a function of NO concentration for a) a heptane concentration of $3.75 \%$ ( $/ \mathrm{v}$ ); and b) an acetonitrile concentration of $1.55 \%(\mathrm{v} / \mathrm{v})$. 
temperatures $30-37^{\circ} \mathrm{C}$, water vapour pressure would be $4.24-6.28 \mathrm{kPa}$, resulting in a decrease of $27-39 \%$ in NO readings. The water vapour content of an exhaled air sample is thus determined by the sample temperature at the analyser's sample inlet, which depends inter alia on the means of sampling and the length of the sample transfer tubings. To avoid variations in NO readings by $\mathrm{CO}_{2}$ and especially by water vapour, which might be of the same magnitude as the differences in NO exhalation described for healthy and asthmatic subjects, the use of both $\mathrm{CO}_{2}$ and water absorbers is recommended [21]. But it has to be considered that, depending on the absorber material, NO adsorption might occur. This is the reason why the use of adsorbers is not recommended in the latest recommendations published by the American Thoracic Society (ATS) [22]. Instead, errors due to humidity should be addressed by each instrument manufacturer or, alternatively, avoided by use of Nafion tubes in the sample line, which equilibrates samples and calibration gas to ambient humidity. Instrument tolerances for quenching by $\mathrm{CO}_{2}$ and water vapour should be $<1 \%$ NO for each $1 \%$ level of interfering compound.

Acetone, heptane and acetonitrile in exhaled air originate either from metabolic processes [16] or from bioaccumulation of inhaled pollutants [15]. Concentrations found in samples of exhaled air from healthy humans were $10-1,000 \mathrm{ng} \cdot \mathrm{L}^{-1}[16]$. Elevated concentrations of acetone may be found in certain diseases (diabetes mellitus [18], chronic heart disease [17]), while heptane and acetonitrile exhalation may be increased for example after occupational exposure. Acetone up to $8.5 \%(\mathrm{v} / \mathrm{v})$, which is well above the concentrations found in patients with diabetes mellitus $(\sim 0.04 \%$ (v/v) [23]), did not influence NO measurements. Heptane and acetonitrile led to marked decreases in NO readings which, in contrast to the findings with $\mathrm{CO}_{2}$ and $\mathrm{H}_{2} \mathrm{O}$, depend both on the concentrations of the interfering compounds and on NO concentration. These results point to a different mechanism of interference. Nevertheless, for heptane and acetonitrile concentrations found in exhaled air of healthy human subjects, the interference is within the range of variation of NO determination and thus might be ignored. Only when higher concentrations of these compounds have to be assumed, for example after occupational exposure, possible interferences have to be considered.

Substances administered in higher concentrations for therapeutic reasons might be another source of interference in NO determination in exhaled air. This might apply for example to $\mathrm{O}_{2}$ in $\mathrm{O}_{2}$ therapy or to volatile anaesthetics, which are major components of exhaled air during surgical operations and recovery from anaesthesia. Increasing the $\mathrm{O}_{2}$ content of samples up to $95 \%(\mathrm{v} / \mathrm{v})$ had no measurable effect on NO determination. Differences observed were within the variation of NO readings. These results differ from those reported for the measurement of NO from combustion systems, where $\mathrm{O}_{2}$ in high concentrations led to a small but significant quenching of the NO signal [13]. Again the use of different analysers might be the reason for these discrepancies.

Monitoring NO in the exhaled air of patients during anaesthesia or during the recovery phase might be of considerable diagnostic importance, for example as an early predictor of sepsis [8]. $\mathrm{N}_{2} \mathrm{O}$ led to marked and significant decreases in NO readings. At anaesthetic concentrations of $60 \% \mathrm{~N}_{2} \mathrm{O}$, a decrease of $36 \%$ was found. Correct NO concentrations might be calculated for the respective chemiluminescence analyser if $\mathrm{N}_{2} \mathrm{O}$ concentrations are known. Thus simultaneous $\mathrm{N}_{2} \mathrm{O}$ monitoring during anaesthesia and during the recovery phase is a prerequisite for precise NO determination.

The halogenated anaesthetic enflurane led to marked decreases in NO readings. However, due to large variations in NO values, this influence was not significant. The main reason for this poor reproducibility was a reaction of enflurane with molybdenum from the converter of the $\mathrm{NO}_{2}$ channel, which resulted in major damage to the analyser. Therefore, NOx analysers with molybdenum converters should not be used with air samples containing halogenated anaesthetics unless the $\mathrm{NO}_{2}$ channel is closed.

With growing knowledge of the pathophysiological role of NO, applications for NO determination in exhaled air as a diagnostic tool will increase. As the chemiluminescence process used for NO quantification is subject to interferences by quenching compounds, a knowledge of these interferences is an urgent need with respect to quality control. The influence of most organic compounds normally present only in low concentrations in exhaled air of healthy subjects is negligible. Interferences from higher concentrated substances (e.g. water vapour, $\mathrm{CO}_{2}$, anaesthetic gases, organic compounds after occupational exposure) have always to be considered. Suitable steps to minimize errors in NO measurements for example according to the recommendations of the ATS [22] should then be taken.

\section{References}

1. Gustafsson LE, Leone AM, Persson MG, Wiklund NP, Moncada S. Endogenous nitric oxide is present in the exhaled air of rabbits, guinea pigs and humans. Biochem Biophys Res Commun 1991; 181: 852-857.

2. Barnes PJ. Nitric oxide and airway disease. Ann Med 1995; 27: 389-393.

3. Lundberg JON, Weitzberg E, Lundberg JM, Alving K. Nitric oxide in exhaled air. Eur Respir J 1996; 9: 26712680.

4. Alving K, Weitzberg E, Lundberg JM. Increased amount of nitric oxide in exhaled air of asthmatics. Eur Respir $J$ 1993; 6: 1268-1270.

5. Barnes PJ. NO or no NO in asthma? Thorax 1996; 51: 218-220.

6. Sumino H, Sato K, Sakamaki T, et al. Decreased basal production of nitric oxide in patients with heart disease. Chest 1998; 113: 317-322.

7. Kharitonov SA, Yates D, Barnes PJ. Increased nitric oxide in exhaled air of normal human subjects with upper respiratory tract infection. Eur Respir J 1995; 8: 295-297.

8. Hussain SNA, Abdul-Hussain MN, El-Dwairi Q. Exhaled nitric oxide as a marker for serum nitric oxide concentration in acute endotoxemia. J Crit Care 1996; 11: 167175.

9. Fajac I, Kahan A, Menkès CJ, Dessanges JF, Dall'AvaSantucci J, Dinh-Xuan AT. Increased nitric oxide in exhaled air in patients with systemic sclerosis. Clin Exp Rheumatol 1998; 16: 547-552.

10. Kharitonov SA, Yates D, Robbins RA, Logan-Sinclair R, Shinebourne E, Barnes PJ. Increased nitric oxide in exhaled air of asthmatic patients. Lancet 1994; 343: 133135 . 
11. Dinh-Xuan AT. Rôle du monoxyde d'azote en physiologic respiratoire et dans la physiopathologie des maladies pulmonaires. Rev Mal Resp 1996; 13: 381-388.

12. Kharitonov S, Alving K, Barnes PJ. Exhaled and nasal nitric oxide measurements: recommendations. Eur Respir $J$ 1997; 10: 1683-1693.

13. Tidona RJ, Nizami AA, Cernansky NP. Reducing interference effects in the chemiluminescent measurement of nitric oxides from combustion systems. JAPCA 1988; 38: 806-811.

14. Zabielski MF, Seery DJ, Dodge LG. Influence of mass transport and quenching on nitric oxide chemiluminescent analysis. Environ Sci Technol 1984; 18: 88-92.

15. Krotoszyoski BK, O'Neill HJ. Involuntary bioaccumulation of environmental pollutants in nonsmoking heterogeneous human population. J Environ Sci Health 1982; A17: 855-883.

16. Krotoszynski B, Gabriel G, O'Neill H, Claudio MPA. Characterization of human expired air: a promising investigative and diagnostic technique. J Chromatogr Sci 1977; 15: 239-244.

17. Skrupsky VA. Gas chromatographic analysis of ethanol and acetone in the air exhaled by the patients. Klin Lab Diagnost 1995; 4: 35-38.

18. Rooth G, Östenson S. Acetone in alveolar air, and in the control of diabetes. Lancet 1966; 19: 1102-1105.

19. Weitz ZW, Birnbaum AJ, Sobotka PA, Zarling EJ, Skosey JL. High breath pentane concentrations during acute myocardial infarction. Lancet 1991; 337: 933-935.

20. Phillips M, Greenberg J. Ion-trap detection of volatile organic compounds in alveolar breath. Clin Chem 1992; 38: $60-65$.

21. van der Mark ThW, Kort E, Meijer RJ, Postma DS, Koëter GH. Water vapour and carbon dioxide decrease nitric oxide readings. Eur Respir J 1997; 10: 2120-2123.

22. American Thoracic Society. Recommendations for standardized procedures for the online and offline measurement of exhaled lower respiratory nitric oxide and nasal nitric oxide in adults and children - 1999. Am J Respir Crit Care Med 1999; 160: 2104-2117.

23. Owen OK, Trapp VE, Skutches CL, et al. Acetone metabolism during diabetic ketoacidosis. Diabetes 1982; 31: 242-248. 